\title{
Crown condition assessment at the CONECOFOR Permanent Monitoring Plots
}

\author{
Filippo BUSSOTTI*, Alberto COZZI ${ }^{1)}$, Marco FERRETTI ${ }^{1)}$, Enrico CENNI ${ }^{1)}$, Davide BETTINI ${ }^{1)}$ and Renzo NIBBI ${ }^{1)}$
}

Università degli Studi di Firenze, Dipartimento di Biologia Vegetale, Piazzale delle Cascine 28, 50144 Firenze, Italy

${ }^{1)}$ Linnaea-ambiente, Via G. Sirtori 37, 50137 Firenze, Italy

*e-mail corresponding author: filippo.bussotti@unifi.it

\section{ABSTRACT}

A detailed crown condition assessment is currently being carried out at the CONECOFOR (CONtrollo ECOsistemi FORestali, Control of Forest Ecosystems) plots. The assessment began in 1996, and during the first two years (1996 and 1997) an assessment form based on previous regional experience was used; in 1998 the new official EU form was adopted. The resulting loss of comparability means that only a few indices can be used in the temporal series 1996-1999. Much effort was devoted to Quality Assurance (QA) procedures. The QA program is structured as follows: (i) specific field manuals have been adopted and are continuously updated; (ii) a national training and intercalibration course (NT\&IC) is undertaken yearly before beginning the assessment campaign;(iii) field checks are carried out yearly on a large number of plots. The results of the QA program have shown that for several indices the quality objectives were not reached, but the quality of the data is improving with time. To express the change in crown conditions in each area, a complex index (CCI = Crown Condition Index) was adopted. This index is the result of the sum of the relativized values of all the common indices used during the four years. The following parameters were used: transparency, ramification type, leaf colour alteration extension, leaf damage extension, alteration of leaf distension extension. The range within which the CCI fluctuates was evaluated taking into account all the observations carried out at a given plot throughout the years. The number of cases over a given threshold (outliers) was calculated for each year. The threshold for outliers was calculated as the median value plus 2 times the range of the interquartile value. All individual cases exceeding this value are considered outliers. The results are presented for all the areas in which the data set is complete for the four years. The yearly fluctuations are discussed and related to possible causes.

Key words: complex indices, crown assessment, outliers, Quality Assurance

\section{INTRODUCTION}

Trees are the most important response indicators adopted by international monitoring programs aimed at assessing air pollution effects on forests in Europe. Besides traditional measurements, such as $\mathrm{DBH}$ and height, the visual assessment of tree crowns has been carried out to evaluate status and trends of tree condition since the early 1980s (e.g. Innes 1993). In particular, within the so-called Level I monitoring network, data relating to two indices, defoliation and discoloration, are collected and the results published yearly by UN-ECE reports (Lorenz et al. 2000).

With the start of the intensive monitoring (Level II) system, a variety of detailed activities began to be undertaken at the monitoring plots, and this calls for a more in-depth assessment of tree condition. In Italy, the assessment of tree condition on Level II Permanent Monitoring Plots (PMPs) started in 1996 and, from the outset, included a specific Quality Assurance (QA) plan (Ferretti et al. 1999). The overall mission of the QA program is to ensure that the quality of data and statistical products is documented and of sufficient quality to satisfy the requirements of data users, policy makers, and the public. The work of the QA team is aimed at the continual improvement of monitoring and assessment activities by identifying, controlling, and documenting errors and variations that are detrimental to the quality of the results provided by crown condition assessments. In this framework, to ensure Standard Operative Procedures (SOPs), methods and manuals developed for regional monitoring programs in Italy (Cenni et al. 1995) were adopted at a national level, since no official manual was initially available. In 1997, the Task Force of the ICP- Forests approved the sub-manual on crown condition (Eichhorn et al. 1996) and in 1998 the same manual was adopted in Italy, replacing the one used previously (Bussotti et al. 1998, 1999). Thus, all "mandatory" and "optional" tree condition indices have been assessed in Italy since 1998 and - to a lesser extent since 1996 (Tab. 1).

Overall, 28 indices are assessed yearly to describe the condition of the trees growing in the Italian Level II PMPs. Of these, only 9 (namely: extent of crown dieback, extent of defoliation, transparency, flowering, fruiting, extent of leaf colour alteration, extent of alteration of leaf distension, extent of leaf damage, regeneration) are evaluated according to a semi-quantitative scoring system, which gives a meaningful ranking of tree condition from a minimum to a maximum.

Paper prepared within the CONECOFOR programme, by the contract with the Ministry for Agriculture and Forestry Policy - National Forest Service, Italy. CONECOFOR is part of the Pan-European Level II Intensive Monitoring of Forest Ecosystem and is co-sponsored by the European Commission. 
Tab. 1. Measurements of Quality Objectives (MQOs) expressed as Data Quality Limits (DQLs). @= agreement. * same scoring system as in the ICP-Forests manual. ${ }^{\circ}$ scoring system consistent with the ICP-Forests manual.

\begin{tabular}{|c|c|c|c|c|}
\hline Tree condition indices & Abbrev. & Year & Unit of measure & DQLs \\
\hline Social status* & Ss & $1996,1998,1999$ & 4 classes & $85 \% @$ \\
\hline Canopy closure* & $\mathrm{Cc}$ & $1996,1998,1999$ & 6 classes & $90 \% @$ \\
\hline Crown dieback - Type & $\mathrm{CdT}$ & 1998,1999 & 6 classes & 90\%@ \\
\hline Crown dieback- Extent & $\mathrm{CdE}$ & 1998,1999 & 22 classes & $90 \% @ \pm 10 \%$ \\
\hline Defoliation - Type & DeT & 1998,1999 & $\begin{array}{l}\text { Norway spruce: } 9 \text { classes } \\
\text { Broadleaves: } 8 \text { classes }\end{array}$ & $90 \% @$ \\
\hline Defoliation - Extent & DeE & 1998,1999 & 22 classes & $90 \% @ \pm 10 \%$ \\
\hline Defoliation Cause & $\mathrm{DeC}$ & 1998,1999 & 32 classes & 90\%@ \\
\hline Transparency* & $\operatorname{Tr}$ & $1996,1998,1999$ & 22 classes & $90 \% @ \pm 10 \%$ \\
\hline Flowering & $\mathrm{F} 1$ & 1998,1999 & 3 classes & 90\%@ \\
\hline Fruiting $^{\circ}$ & $\mathrm{Fr}$ & $1996,1998,1999$ & 3 classes & 90\%@ \\
\hline Leaf colour alteration - Type $^{\circ}$ & LcaT & $1996,1998,1999$ & 7 classes & $90 \% @$ \\
\hline Leaf colour alteration - Extent* & LcaE & $1996,1998,1999$ & 22 classes & $85 \% @ \pm 20 \%$ \\
\hline Leaf colour alteration - Leaf localization & LcaLL & 1998,1999 & 10 classes & 85\%@ \\
\hline Leaf colour alteration - Crown localization & LcaCL & 1998,1999 & 7 classes & $85 \% @$ \\
\hline Foliage age interested by colour alteration & $\mathrm{Fa}$ & 1998,1999 & 4 classes & 85\%@ \\
\hline Leaf colour alteration - Cause & $\mathrm{LcaC}$ & 1998,1999 & 20 classes & $90 \% @$ \\
\hline Size of leaves ${ }^{\circ}$ & $\mathrm{Sl}$ & $1996,1998,1999$ & 4 classes & $90 \% @$ \\
\hline Alteration of leaf distension- Type & AldT & 1998,1999 & 7 classes & $90 \% @$ \\
\hline Alteration of leaf distension - Extent ${ }^{\circ}$ & AldE & $1996,1998,1999$ & 22 classes & $90 \% @ \pm 10 \%$ \\
\hline Leaf damage - Type & LdT & 1998,1999 & 18 classes & 90\%@ \\
\hline Leaf damage - Extent* & $\mathrm{LdE}$ & $1996,1998,1999$ & 22 classes & $90 \% @ \pm 10 \%$ \\
\hline Ramification - Type $^{\circ}$ & $\operatorname{RaT}$ & $1996,1998,1999$ & $\begin{array}{c}\text { Norway spruce: } 4 \text { classes } \\
\text { Beech: } 5 \text { classes }\end{array}$ & 90\%@ \\
\hline Regeneration $^{\circ}$ & $\operatorname{Re}$ & $1996,1998,1999$ & 3 classes & $90 \% @$ \\
\hline Epiphytes $^{\circ}$ & Ep & $1996,1998,1999$ & 11 classes & $90 \% @$ \\
\hline Ramification damage - Type & RadT & 1998,1999 & 9 classes & 90\%@ \\
\hline Ramification damage - Localization & $\operatorname{RadL}$ & 1998,1999 & 5 classes & $90 \% @$ \\
\hline Stem damage - Type & $\mathrm{SdT}$ & 1998,1999 & 16 classes & $90 \% @$ \\
\hline Stem damage - Localization & $\mathrm{SdL}$ & 1998,1999 & 7 classes & 90\%@ \\
\hline Damage by Insects & DI & 1996 & 5 classes & $90 \% @$ \\
\hline Damage by Fungi & $\mathrm{DFu}$ & 1996 & 5 classes & 90\%@ \\
\hline Damage by Game & DG & 1996 & 5 classes & $90 \% @$ \\
\hline Damage by Fire & DFi & 1996 & 5 classes & $90 \% @$ \\
\hline Damage by direct action of man & DAm & 1996 & 5 classes & $90 \% @$ \\
\hline Damage by Meteorological events & $\mathrm{DMe}$ & 1996 & 5 classes & $90 \% @$ \\
\hline Damage by Acute pollution & DAp & 1996 & 5 classes & $90 \% @$ \\
\hline
\end{tabular}

Tree condition is subject to fluctuation and changes over time and around a "mean" status that is dependent on many factors, including species, age and site condition. The expression of this "mean" status is also dependent on the indicator/indices adopted: for example, defoliation and discoloration can have substantially different causes and may not be present at the same time on the same trees. Thus, although it is not easy to say whether a defoliated tree is in better condition than a discoloured one, we can state that a tree showing both discoloration and defoliation is in a worse condition than a tree displaying - to the same extent - only one of the two symptoms. When several indices are used, then, it is important to have a synthetic expression of tree status (e.g. Muir \& McCune 1987, Mc Laughlin et al. 1992) that can help identify any anomalous deviation from the "mean" condition.

The aims of this paper are to provide data about the quality of crown condition assessment collected in Italy between 1996 and 1999 in the Level II plots, and to evaluate the status of the sample trees and the potential causes of critical situation that they may have experienced over the same period.

\section{MATERIAL AND METHODS}

\subsection{Indices}

The indices used to assess the tree condition, the year of adoption, the reporting units, the Measurement Quality Objectives (MQOs) and the Data Quality Limits (DQLs) set for each index according to the system adopted by the Environmental Monitoring and Assessment Programme - Forest Health Monitoring Programme of the US Environment Protection Agency (US/EPA-EMAP-FHM, Tallent-Halsell 1994) are illustrated in table 1 . The indices adopted in 1996 were not exactly the same as those used in 1998 and 1999. Thus, in the first year of the CONECOFOR programme, crown condition assessment involved only a few indices with the same scoring system as in the ICP-Forests Manual, or a system consistent with it. After being officially approved, the ICP-Forests manual was adopted 
starting in 1998, and is still being used (Bussotti et al. 1999).

\subsection{Quality Assurance (QA) procedures}

The procedures adopted in Italy include:

(i) the use of SOPs, consisting of field manuals (Bussotti et al. 1999, Müller \& Stierlin 1990, Ferretti 1994);

(ii) the establishment of MQOs expressed by DQLs for each tree condition index (Tab. 1),

(iii) a yearly National Training and Intercalibration Course (NT\&IC) to provide surveyors with standard guidelines and to obtain the highest possible homogeneity and harmonisation in the evaluation;

(iv) field checks (FC), performed on a number of plots previously assessed by the field crews, to test the reproducibility of the field data;

(v) control of the completeness, consistency and plausibility of the data before their final registration in the archives.

Field assessment of crown condition at the PMPs of the CONECOFOR program is usually carried out by local foresters (university graduates). Since in the majority of cases there is one evaluation team for each Italian region (the only exceptions being Friuli, Lombardy and Tuscany) the usual procedure is to have one field crew for each PMP: these crews are referred to as "observers". During the NT\&IC the observers are first instructed by the QA (control) team on various (usually 5-10) different trees that are taken as examples of different assessment problems. After this, the observers evaluate separately a number (25-30) of trees representing each of the most important species they will find in their PMPs: Fagus sylvatica L. (beech); Quercus cerris L. (Turkey oak) and Picea abies (L.) Karst (Norway spruce).

In the 1996-1999 period all the PMPs were checked. Nine PMPs were assessed at the same time by both the observer and the QA team, while the QA team assessed 4 PMPs some time after the observer team and 3 PMPs before. In 1999 the data of VEN 1 were seriously affected by the fact that the assessments were performed in different periods, because a hail-storm had influenced several indices such as defoliation, transparency, leaf damage and colour. In this case the data were excluded from the processing.

\subsection{Data sets and statistics}

The data used for the various analyses are those collected on the various PMPs between 1996 and 1999. In the processing, only the PMPs (14) that have complete data sets for each of the 4 years were considered. As two different manuals were adopted in 1996-97 and 1998-99, only those indices in common between the two manuals were considered (Tab. 1). When the two manu- als used different scoring systems for the same indices, the 1996-97 data were re-scaled to be in line with the scoring system provided by Eichhorn et al. (1996).

When many indices are used, the problem arises of trying to synthesize them into a more simple expression. After a consideration of both statistically formalized and conceptual approaches (Bussotti et al. 2000), the latter was chosen. The Crown Condition Index (CCI) was calculated for each species and PMP (Bussotti et al. 2000) using the following parameters: transparency ( $\mathrm{Tr})$, type of ramification (RaT), extension of leaf colour alteration $(\mathrm{LcaE})$, extension of leaf damage ( $\mathrm{LdE})$, extension of the alteration of leaf distension (AldE). Then the CCI was calculated for each tree by the sum of these values, as follows:

(i) beech, turkey oak, sessile oak:

$$
C C I_{\text {tree }}=I_{\text {rel }} T r+I_{\text {rel }} R a T+I_{\text {rel }} L c a E+I_{\text {rel }} L d E+I_{\text {rel }} A l d E
$$

(ii) Norway spruce:

$$
C C I_{\text {tree }}=I_{\text {rel }} T r+I_{\text {rel }} l L c a E+I_{\text {rel }} L d E
$$

(iii) European hornbeam:

$$
C C I_{\text {tree }}=I_{r e l} T r+I_{r e l} L c a E+I_{r e l} L d E+I_{r e l} A l d E
$$

where:

$C C I_{\text {tree }}=$ Crown Condition Index for individual trees;

$I_{r e l}=$ relativized index (a-dimensional) for the various original indices given by:

$$
I_{\text {rel }}=\left(I_{\text {actual }}-I_{\min }\right) / I_{\max } \text {, }
$$
where:

$I_{\text {actual }}=$ actual score for the original index;

$I_{\min }=$ minimum possible score for the original index;

$I_{\max }=$ maximum possible score for the original index.

The score for the PMP was calculated by means of the $\mathrm{CCI}_{\text {tree }}$ values:

$$
C C I_{P M P}=\frac{\sum_{1}^{N} C C I_{\text {tree }}}{N}
$$

where:

$C C I_{P M P}=$ Crown Condition Index for the PMP;

$N=$ number of trees assessed.

Finally, the range within which the CCI fluctuates was evaluated taking into account all the observations carried out at a given PMP throughout the years. Then the number of cases over a threshold (outliers) was calculated for each year. The threshold for outliers was calculated as the median value plus 2 times the range of the interquartile value. All individual cases exceeding this value are considered outliers.

\section{RESULTS}

\subsection{Quality Assurance}

The results of NT\&IC and FC are presented in table 2 and figure 1. Of the common indices recorded in the NT\&IC between 1996 and 1999, leaf colour diffusion 
reached the DQLs in all the years, while leaf size and leaf damage diffusion did not in 1998 and 1999 respectively.

The level of reproducibility of social status, canopy closure, alteration of leaf distension and regeneration was drastically reduced between 1996 and the following years, probably because of the different scoring system; epiphytes remained at the same level ( $\mathrm{ca}$ 90\%). Among the indices assessed in 1998 and 1999, only flowering reached the DQLs in both years, while crown dieback 
producibility decreased drastically between 1996 and the following years, while ramification type presented inconsistent results. Among the indices assessed only in 1998 and 1999, flowering and stem damage localization reached the DQLs in both years. The number of indices reaching the DQLs increased over the two years: 3 in 1998, 11 in 1999.

Comparing the NT\&IC and FC data between 1998 and 1999, the main results are:

- crown dieback extent, defoliation type and extension, leaf damage type, ramification damage type and localization registered an increase in the levels of agreement over the two years both in the NT\&IC and FC;

- canopy closure, defoliation type and regeneration always presented a low level of reproducibility, both in the NT\&IC and FC;

- when for the same parameter two or more indices were assessed (i.e. type and extension), the "type" component had a lower reproducibility (e.g. in defoliation, alteration of leaf distension and leaf damage);

- transparency never reached the DQLs either in NT\&IC or in FC, but had a stable value of agreement of around $80 \%$.

\subsection{Tree condition}

The condition of the crowns, expressed by CCI, varies according to the PMP and its basic ecological features. The variations in tree conditions are expressed, for each individual PMP, as the number of outliers per year. The main results are summarized in tables 3-4. The differences among the outlier threshold values were very marked also within the same species, indicating very variable ecological conditions among the sites. Results are reported for the three main species. It should be noted that crown transparency, i.e the most common index for extensive surveys of tree conditions, plays a very small role in determining the year to year variations in the overall CCI.

Beech. The differences between years are site-specific and no common trend is easily detectable. Outliers occurred in only 1 year in ABR1 (1999); in two years in CAL1 (1998 and 1999), in CAM1 (1996 and 1998) and in EMI2 (1997 and 1999); in all years in PIE1. The most common critical factor (i.e. one responsible for threshold exceedance) is leaf damage, indicating the importance of occasional events (e.g. drought, pests and diseases) in determining tree condition. Branching was also important as a cause of outliers, but the low reproducibility of this parameter makes interpretation doubtful. Transparency was an important factor in PIE1 in 1998.

Norway spruce. There was no common trend between PMPs. Outliers occurred between 1997, 1998 and 1999 (TRE1) and 1996 and 1998 (FRI2). The most common indices determining threshold exceedance were leaf damage extent (TRE1) and leaf colour alteration extent for FRI2.

Turkey oak. Outliers for Turkey oak PMPs occurred in 1996 and 1997 (LAZ1), 1998 (MAR1), 1998 and 1999 (UMB1). The indices determining the threshold exceedance were branching for LAZ1, whereas the UMB1 and MAR 1 outliers were due to the high score of leaf condition (leaf malformations and leaf damage in UMB1 and leaf colour extent and leaf malformations in MAR1).

\section{DISCUSSION AND CONCLUSIONS}

The sub-program Crown Condition of CONECOFOR began in 1996, with the Quality Assurance program as an essential part of it. The aim of the QA program was to identify methodological problems and to check the

Tab. 3. Median, interquartile range, outlier threshold (median plus 2 times the interquartile range) and outlier occurrence (n outliers) in each year.

\begin{tabular}{|c|c|c|c|c|c|c|c|c|c|}
\hline \multirow[t]{2}{*}{ Specie } & \multirow[t]{2}{*}{ PMP } & \multirow[t]{2}{*}{$\mathrm{n}$} & \multirow[t]{2}{*}{ Median } & \multirow[t]{2}{*}{ Interquartile } & \multirow[t]{2}{*}{ Outlier threshold } & \multicolumn{4}{|c|}{ n outliers } \\
\hline & & & & & & 1996 & 1997 & 1998 & 1999 \\
\hline \multirow[t]{5}{*}{ Beech } & ABR1 & 116 & 0,425 & 0,375 & 1,175 & 0 & 0 & 9 & 0 \\
\hline & CAL1 & 118 & 0,613 & 0,275 & 1,163 & 0 & 0 & 6 & 1 \\
\hline & CAM 1 & 120 & 0,450 & 0,225 & 0,900 & 2 & 0 & 2 & 0 \\
\hline & EMI 2 & 118 & 0,350 & 0,200 & 0,750 & 0 & 10 & 0 & 2 \\
\hline & PIE 1 & 87 & 0,450 & 0,300 & 1,050 & 1 & 3 & 1 & 1 \\
\hline \multirow[t]{3}{*}{ Turkey oak } & LAZ 1 & 118 & 0,325 & 0,125 & 0,575 & 1 & 2 & 0 & 0 \\
\hline & MAR & 106 & 0,475 & 0,200 & 0,875 & 0 & 0 & 3 & 0 \\
\hline & UMB 1 & 114 & 0,450 & 0,275 & 1,000 & 0 & 0 & 1 & 2 \\
\hline Holm oak & TOS 1 & 120 & 1,025 & 0,587 & 2,200 & 0 & 0 & 1 & 0 \\
\hline Sessile oak & EMI 1 & 82 & 0,500 & 0,325 & 1,150 & 2 & 2 & 1 & 1 \\
\hline \multirow[t]{4}{*}{ Norway spruce } & FRI 2 & 119 & 0,250 & 0,150 & 0,550 & 2 & 0 & 5 & 0 \\
\hline & LOM 1 & 74 & 0,200 & 0,200 & 0,600 & 0 & 0 & 0 & 0 \\
\hline & TRE 1 & 119 & 0,200 & 0,100 & 0,400 & 0 & 3 & 1 & 1 \\
\hline & VAL 1 & 120 & 0,300 & 0,175 & 0,650 & 0 & 0 & 0 & 0 \\
\hline
\end{tabular}


Tab. 4. Critical years, critical indices and possible cause of critical conditions for each PMP. $\mathrm{PMP}=$ Permanent Monitoring Plot; transparency $(\mathrm{Tr})$, ramification - type (RaT), leaf colour alteration - extension (LcaE), leaf damage - extension (LdE), leaf colour extent (LCE); alteration of leaf distension - extension (AldE)

\begin{tabular}{|c|c|c|c|c|}
\hline Species & PMP & Critical year & Critical indices & Possible causes \\
\hline Beech & $\begin{array}{l}\text { ABR1 } \\
\text { CAL1 } \\
\text { CAM } 1 \\
\text { EMI } 2 \\
\text { PIE } 1\end{array}$ & $\begin{array}{l}1998 \\
1998 \\
1999 \\
1996 \\
1998 \\
1997 \\
1999 \\
1996 \\
1997 \\
1998 \\
1999\end{array}$ & $\begin{array}{c}\text { RaT } \\
\text { LdE } \\
\text { LdE } \\
\text { RaT } \\
\text { LdE } \\
\text { LdE } \\
\text { LdE } \\
\text { LcaE } \\
\text { LcaE } \\
\text { Tr, RaT } \\
\text { AldE, LdE }\end{array}$ & $\begin{array}{c}\text { Possible observer bias } \\
\text { Leaf miners (Rhynchaenus fagi) } \\
\text { Leaf miners (Rhynchaenus fagi) } \\
\text { Possible observer bias } \\
\text { Defoliator insects } \\
\text { Defoliator insects } \\
\text { Defoliator insects } \\
\text { Fungi } \\
\text { Climatic stress } \\
\text { Defoliator insects } \\
\text { Defoliator insects }\end{array}$ \\
\hline Turkey oak & $\begin{array}{l}\text { LAZ } 1 \\
\text { MAR } \\
\text { UMB } 1\end{array}$ & $\begin{array}{l}1996 \\
1997 \\
1998 \\
1998 \\
1999\end{array}$ & $\begin{array}{c}\text { RaT } \\
\text { RaT } \\
\text { LcaE, AldE } \\
\text { AldE, LdE. LcaE } \\
\text { AldE, LdE }\end{array}$ & $\begin{array}{l}\text { Past complex stress conditions } \\
\text { Past complex stress conditions } \\
\text { Defoliator insects } \\
\text { Drought and fungi } \\
\text { Drought and fungi }\end{array}$ \\
\hline Holm oak & TOS 1 & 1998 & RaT, LcaE & Fungi and snow damage \\
\hline Sessile oak & EMI 1 & $\begin{array}{l}1996 \\
1997 \\
1998 \\
1999\end{array}$ & $\begin{array}{l}\text { RaT } \\
\text { RaT } \\
\text { LdE } \\
\text { LdE }\end{array}$ & $\begin{array}{l}\text { Past complex stress conditions } \\
\text { Past complex stress conditions } \\
\text { Defoliator insects } \\
\text { Defoliator insects }\end{array}$ \\
\hline Norway spruce & $\begin{array}{l}\text { FRI } 2 \\
\text { TRE } 1\end{array}$ & $\begin{array}{l}1996 \\
1998 \\
1997 \\
1998 \\
1999\end{array}$ & $\begin{array}{l}\mathrm{LdE} \\
\mathrm{LcaE} \\
\mathrm{LdE} \\
\mathrm{LdE} \\
\mathrm{LdE}\end{array}$ & $\begin{array}{l}\text { Fungi } \\
\text { Unidentified } \\
\text { Fungi } \\
\text { Fungi } \\
\text { Fungi }\end{array}$ \\
\hline
\end{tabular}

reproducibility of the field data. In 1998 the ICP-Forests Manual was adopted and, as a result, some problems of comparability with the previous year arose.

Besides the new indices, the main differences between the two methods regarded the different scoring system of some indices. Another problem was the introduction of new indices that demanded a new "learning phase" (Innes 1988; Innes \& Boswell 1990). Some parameters, e.g. ramification, displayed low levels of reproducibility because they present intrinsic difficulties, and their definition must be better explained in the manuals. It is important to note that in most cases the results provided by field check (FC) data had better reproducibility than NT\&IC. From 1998 to 1999 the number of indices reaching DQLs in the FC increased: 5 in 1998 (flowering, colour leaf extent, leaf size, ramification, stem damage type and localization), 8 in 1999 (crown dieback extent, colour leaf extent, colour leaf localization leaf, leaf size, leaf alterations, ramification damage type, stem damage type and localization). The Crown Condition Index (CCI) used to evaluate the dynamics of tree conditions is made up of the sum of several indices. Only in a few cases did these indices reach the DQLs (leaf damage extent in 1996, colour damage extent in 1998 and 1999, leaf alterations in 1999 and ramification in 1998), while transparency never did. So, the poor reproducibility of individual indices affects the internal consistency of CCI. However, because the number of indices reaching DQLs is increasing, the CCI can incorporate more effective parameters or substitute those with lesser reproducibility. For example, the new assessment form adopted in 1998 includes some new observations (crown dieback extent, defoliation extent). In this case the historical series have to be re-calculated according to the new criteria. Nevertheless some limitations are evident:

- outliers represent the behaviour of individual trees which exceed a given threshold, but give us little information about the whole population;

- currently, the various indices are not weighted differently because it is difficult to attribute to each of them an exact biological/ecological meaning. Thus, the relationships resulting between the indices may be unbalanced, with a loss of information.

The results obtained up to now must be considered as indicative of the potential offered by this methodology, and of its limits. Four years are too short a period to detect possible temporal trends in crown conditions and, excluding the possible bias deriving from the low reproducibility of some indices, the interannual differences are due to the occasional interference of biotic and abiotic stress agents.

\section{ACKNOWLEDGMENTS}

This paper was prepared as part of the contract between the Ministry for Agriculture and Forestry Policy - 
National Forest Service (co-ordinator of the CONECOFOR Program, National Focal Center - Italy) and the Department of Plant Biology, University of Florence, Italy. The authors are grateful to their coworkers who perform the field work, the whole Quality Assurance programme and the data management.

\section{REFERENCES}

Bussotti, F., M. Ferretti, A. Cozzi \& E. Cenni. 1998. Condizione delle chiome degli alberi. Valutazione nelle aree permanenti di livello $2^{\circ}$. Manuale di campagna. (Maggio 1998, Revisione 0). Ministero per le Politiche Agricole, Roma: 80 pp.

Bussotti, F., M. Ferretti, A. Cozzi \& E. Cenni. 1999. Condizione delle chiome degli alberi. Valutazione nelle aree permanenti di livello $2^{\circ}$. Manuale di campagna. (Maggio 1999, Revisione 1). Ministero per le Politiche Agricole, Roma: $92 \mathrm{pp}$

Bussotti, F., M. Ferretti P. Giordano\& C. Mazzali. 2000. A synthetic index to estimate tree condition in the Permanent Monitoring Plots of the CONECOFOR program. Ann. Ist. Sperim. Selvic. Special Issue, 30: 67-72.

Cenni, E., A. Cozzi, M. Ferretti \& F. Bussotti. 1995. Valutazione delle condizioni degli alberi-Manuale per le aree di Livello I. Regione Toscana-Giunta regionale: $126 \mathrm{pp}$.

Eichorn, J., M. Ferretti, J.L. Innes, P. Roskams \& E. Vel. 1996. Visual assessment of tree condition. UN/ECE ICPForests, Manual on method and criteria for harmonized sampling, assessment, monitoring and analysis of the effects of air pollution on forests. $4^{\text {th }}$ edition.
Ferretti, M. (Ed.) 1994. Mediterranean Forest Trees. A Guide For Crown Assessment, CEC - UN/ECE, Brussels, Geneva.

Ferretti, M., F. Bussotti, E. Cenni \& A. Cozzi. 1999. Implementation of quality assurance procedures in the Italian programs of forest condition monitoring. Water Air Soil Pollut., 116: 371-376.

Innes, J.L. 1988. Forest Health Surveys: problems in Assessing Observer Objectivity. Can. J. For. Res., 18: 560-565.

Innes, J.L. \& R.C. Boswell. 1990. Reliability, presentation, and relationships among the data from inventories of forest condition. Can. J. For. Res., 20:790-799.

Innes, J.L. 1993. Forest Health: its Assessment and Status. Commonwealth Agricultural Bureau, Wallingford.

Lorenz, M., G. Becher, R. Fischer \& W. Seidling. 2000. Forest condition in Europe. Prepared by: Federal Research Centre for Forestry and Forest Products (BFH). Hamburg, Germany: pp. $86+$ Annexes.

Mc Laughlin, D., W. Gizyn, W. Mcilveen \& C. Kinch. 1992. A quantitative tree crown rating system for deciduous forest health surveys: some results for Ontario. In: Manion, P. D. \& D.Lachance (Eds), Forest decline Concepts. APS Press; The American, Phytopatological Society, St. Paul, Minnesota: 137-154.

Muir, P.S. \& B. McCune. 1987. Index Construction for Foliar Symptoms of Air Pollution Injury. Plant Disease, 71: 558565 .

Müller, E. \& H.R. Stierlin. 1990. Sanasilva. Tree crown photos. Swiss Federal Institute for Forest, Snow and Landscape Research, Birmensdorf: pp.129.

Tallent-Halsell, N.G. 1994. Forest Health Monitoring 1994. Field Methods Guide. PA/620/R-94/027. U.S. Environmental Protection Agency, Washington, D.C. 